\title{
BMJ Open Multidisciplinary approach to the management of children with female genital mutilation (FGM) or suspected FGM: service description and case series
}

\author{
Sarah M Creighton, ${ }^{1}$ Joanna Dear, ${ }^{1}$ Claudia de Campos, ${ }^{1}$ Louise Williams, ${ }^{1}$ \\ Deborah Hodes ${ }^{2}$
}

To cite: Creighton SM, Dear J, de Campos C, et al. Multidisciplinary approach to the management of children with female genital mutilation (FGM) or suspected FGM: service description and case series. BMJ Open 2016;6: e010311. doi:10.1136/ bmjopen-2015-010311

- Prepublication history for this paper is available online. To view these files please visit the journal online (http://dx.doi.org/10.1136/ bmjopen-2015-010311).

Received 21 October 2015 Revised 15 January 2016 Accepted 11 February 2016

CrossMark

\footnotetext{
1Department of Women's Health, University College London Hospital, London, UK ${ }^{2}$ Department of Paediatrics, University College London Hospital, London, UK
}

Correspondence to Sarah Creighton; sarah.creighton@uclh.nhs.uk

\section{ABSTRACT}

Objective: To describe the first dedicated clinic in the UK for children with suspected or confirmed female genital mutilation (FGM) including referral patterns, clinical findings and subsequent management.

Design and setting: A prospective study of all children seen in a dedicated multidisciplinary FGM clinic for children over a 1-year period.

Population: Patients aged under 18 years referred for clinical assessment or for a second opinion on Digital Versatile Disc (DVD) images.

Methods and main outcome measures: Data were collected on reasons for referral, demography, genital examination findings including FGM type, and clinical recommendations.

Results: 38 children were referred of whom 18 (47\%) had confirmed FGM; most frequently type 4 (61\%). Social care and police referred $78 \%$ of cases. According to UK law FGM had been performed illegally in three cases. Anonymous information given to the police led to the referral of six children, none of whom had had FGM.

Conclusions: Mandatory reporting and increased media attention may increase the numbers of referrals of children with suspected FGM. This patient group have complex needs and management in a dedicated multidisciplinary service is essential. Paediatricians and gynaecologists should have the skills to carry out the consultation and detect all types of FGM including type 4 which was the most common type seen in this series. This is the first dedicated FGM service for children in the UK and similar clinics in highprevalence areas should be established.

\section{INTRODUCTION}

Female genital mutilation (FGM) is almost always performed on children and recent guidance from the Department of Health has highlighted the importance of identifying and referring girls who have had or are

\section{Strengths and limitations of this study}

- Up to date information is needed on female genital mutilation (FGM) practices among migrant communities living in the UK to inform prevention work and to ensure adequate clinical services for affected children.

- This small study is the first to describe FGM in children resident in the UK. This unique data add valuable clinical information about children living in FGM practising communities in the UK diaspora.

- The final criminal outcomes are unknown as legal proceedings are still on-going. More research on the psychological impact of referral to the clinic is awaited.

at risk of FGM. ${ }^{1}$ Early detection allows appropriate medical attention and may protect siblings and other girls in the family against FGM. The Serious Crime Act, 2015, makes it mandatory from 31.10.15 for all professionals in health, education and social services to report to the police within 1 month, all under 18-year-olds who have signs of FGM or who say they have undergone FGM. ${ }^{2}$ The introduction of this guidance and the surrounding intense media focus may increase the number of children needing expert evaluation. Despite this expectation, little attention has been paid to best service provision. Paediatricians seeing children for suspected or alleged sexual abuse are experienced in genital examination but may be unfamiliar with the different types of FGM particularly where physical signs are minimal or absent. ${ }^{3}$ Obstetricians, gynaecologists and midwives are expected to be more familiar with the health implications of FGM although this is not always the case. ${ }^{4}$ In 


\begin{tabular}{|c|c|}
\hline Type & WHO description \\
\hline 1 & $\begin{array}{l}\text { Partial or total removal of the clitoris and/or the } \\
\text { prepuce. }\end{array}$ \\
\hline 2 & $\begin{array}{l}\text { Partial or total removal of the clitoris and the labia } \\
\text { minora, with or without excision of the labia majora. }\end{array}$ \\
\hline 3 & $\begin{array}{l}\text { Narrowing of the vaginal orifice with the creation of } \\
\text { a covering seal by cutting and appositioning the } \\
\text { labia minora and/or the labia majora, with or } \\
\text { without excision of the clitoris. }\end{array}$ \\
\hline 4 & $\begin{array}{l}\text { All other harmful procedures to the female genitalia } \\
\text { for non-medical purposes, for example: pricking, } \\
\text { piercing, incising, scraping and cauterisation. }\end{array}$ \\
\hline
\end{tabular}

addition as adult clinicians, they are not generally trained in the examination of children and are less used to working with social care or the police. A lack of rigorous UK research combined with secrecy surrounding the procedure means there is scant knowledge about the health implications of FGM in children. Little is known on attitudes to or prevalence of FGM among diaspora communities and the impact of a referral on the family as mandated is unknown.

FGM referrals to the children's safeguarding clinic (DH) and paediatric gynaecology services (SMC) had increased over the previous 7 years from only 1 referral in 2007 to 17 referrals in $2013 .^{5}$ As a result the UK's first paediatric FGM service was established in 2014 comprising a monthly multidisciplinary clinic with input from child psychotherapy and specialist nursing.

This study describes the activity of the first year of the clinic which includes referral and clinical management of children along with giving second opinions. Patterns, trends and clinical pitfalls are explored. The study provides important information for clinicians and commissioners who may need to make future provision for increasing numbers of children requiring specialised clinical care and assessment for FGM.

\section{METHODS}

The local Research Ethics Committee approved the study, providing the analysis and publication excluded all patient identifiable information. Data were collected prospectively for 1 year from September 2014 of all children referred to a dedicated children's FGM clinic in an inner London teaching hospital with confirmed or suspected FGM. Data included referral, history, examination findings and subsequent clinical management.

The clinic is set in paediatric outpatients. It is led by a paediatric consultant (DH) with experience in child maltreatment, including child sex abuse, and a paediatric and adolescent gynaecologist with experience in FGM management (SMC). An experienced child psychotherapist $(\mathrm{CdC})$ and a specialist nurse in paediatric and adolescent gynaecology (LW) both attend and there is also play specialist support. Independent interpreters and telephone interpreters are available if required and family members or friends are not asked to interpret. $\mathrm{DH}$ and SMC jointly perform a genital examination using a colposcope. Written consent is obtained from the parent, if the child is aged under 16 years, or from the child if over 16 years to record the colposcopic examination on Digital Versatile Disc (DVD). The diagnosis of FGM in each case is made on either a clear history of FGM given by the girl or her family or evidence of FGM seen on genital examination in the clinic. The WHO classification ${ }^{6}$ is used to describe the type of FGM if present (table 1).

Where FGM is confirmed, testing for blood-borne viruses (BBV) is recommended because of the circumstances of the procedure and other tests may be offered if clinically indicated such as a measurement of vitamin D levels. If required, deinfibulation is performed by SMC within a paediatric surgical setting at a later date. If declined by the young person, information is given as to how to access the procedure in future.

Following the consultation, the findings are explained to the parents, social worker and police if present. The explanation given to the child will depend on the individual child's age and level of understanding. If required, an explanation on the genital anatomy, the significance of the FGM and what it means for their future health is given. The UK law with regard to FGM is explained if parents are unaware of it. Immediately following the FGM assessment the children and families are routinely offered a debriefing session with the child psychotherapist. The structure and content of the debriefing process takes the developmental stage of the child or young person. It may involve the child or young person alone, the parents only or the whole family. From time to time the social worker is also included. The FGM investigation may also have opened up other concerns in relation to cultural dislocation, marginalisation and stigma. A small number of follow-up psychotherapy sessions can be provided in the clinic but children are referred back to local child mental health services for longer term support. Parents are given contact details of the charity FORWARD (Foundation for Women's Health and Research) ${ }^{7}$ for support and further information and the Home Office Statement Opposing FGM-the 'FGM passport'. ${ }^{8}$ A medical report of the findings is sent to the referrers, General Practitioner (GP) and parents, and witness statements are provided if requested by the police.

\section{RESULTS}

Of the 38 children and young girls aged under 18 years referred, 30 attended the clinic in person while eight referrals were for a second opinion on DVD images of a genital examination. Social care and police accounted for $74 \%$ of referrals with the remainder from midwives $(n=1)$, paediatric consultants $(n=3)$ and solicitors $(n=3)$. Five children came to the attention of social care or 


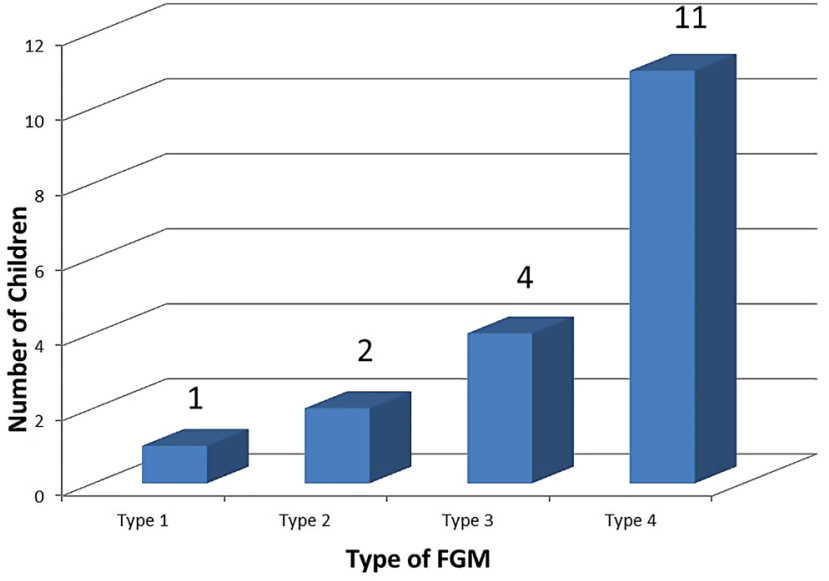

Figure 1 Clinical examination findings of FGM type. FGM, female genital mutilation.

police as a result of anonymous information. The time taken between authorities being made aware of the case and referral to the clinic was on average 7 weeks (range 4 days-24 weeks). The time between receipt of the referral and an appointment was on average 12.5 days.

Of the 38 children, $18(47 \%)$ were confirmed as having FGM due to the history given or genital examination findings. No child was referred acutely with signs of recent FGM. In 15 cases, the parents were aware their child had FGM and in three cases the parents claimed to be unaware their child had FGM. Only 1 of the 18 cases was referred due to physical symptoms-poor urinary flow in a 15-year old girl due to type 3 FGM. All others had been referred by social care and police who were undertaking an investigation as to whether the child was at risk of significant harm as required by section 47 of the 1989 Children Act. The type of FGM was classified using the WHO criteria (figure 1). Of the 11 children with a diagnosis of type 4 FGM, 10 had a small visible scar (figure 2). In the patient without a scar, the family confirmed that the girl had been cut some years previously. In 17 of the 18 cases the child's country of birth was known and were Somalia $(n=13)$, UK ( $n=2)$, Saudi Arabia $(n=1)$ and Gambia $(n=1)$. All girls with type 3 FGM were of Somalian origin and had undergone FGM in Somalia.

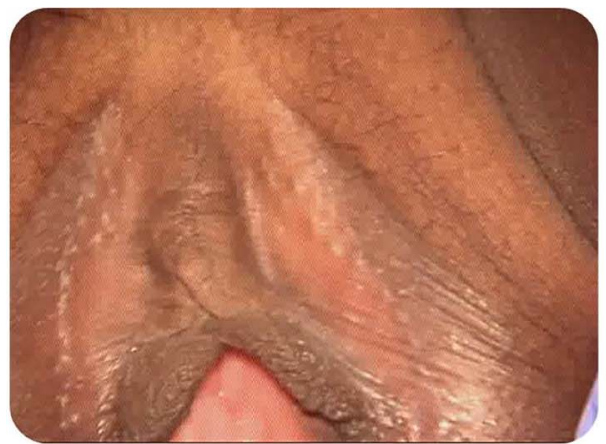

The mean age of FGM was 6.8 years (range 7 months10 years). In 13 cases, information was available regarding the background of the person who had carried out the FGM. Of these $62 \%$ were said to have been carried out by health professionals. The remainder $(38 \%)$ were carried out by traditional circumcisers or family members. In over a third $(38 \%)$ the procedure took place in a clinic or hospital. No parent recalled any immediate health complications following their daughter's FGM.

All children who were tested for BBV tested negative. Deinfibulation was offered to the four girls with type 3 FGM. These girls were aged 18, 17, 15 and 9 years. Three of the girls had no symptoms related to their FGM. One girl (age 15) had a slow urinary stream but no other urinary symptoms. The need for deinfibulation prior to sexual activity was discussed with the girls and their parents. All four girls and parents confirmed they would prefer to wait until they were planning marriage. The three oldest girls were given contact details for the adult FGM clinic to access deinfibulation when they were ready.

Of the 18 cases with confirmed FGM, 15 were performed before the child entered the UK and thus were not illegal under UK law. Three cases were identified as illegal under UK law. One girl alleged that she underwent FGM in her bedroom in London at the age of 10 performed by two women her mother had brought to the house. She was cut along with her sister and two cousins. Type 2 FGM was confirmed on examination in the clinic but as yet no further police action has been taken. One child was allegedly subjected to FGM while on a family holiday in Oman and DVD review confirmed as small scar consistent with type 4 FGM. One child's parents took her to Malaysia at the age of 7 months and a prick was made to the clitoris by a practitioner at the local hospital with parental consent. The parents were unaware that this traditional practice constituted FGM. There were no visible signs on examination confirming a diagnosis of FGM and a diagnosis of type 4 was made on history alone. Both of these latter cases are under investigation by the police.

Sixteen families (42\%) accepted the offer of an immediate debriefing assessment with the psychotherapist

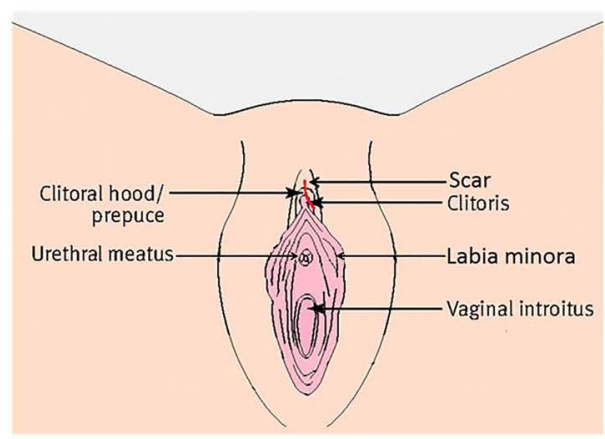

Figure 2 Type 4 FGM with corresponding diagram. FGM, female genital mutilation. 
immediately after the clinical assessment. Following this assessment four children were offered follow-up psychotherapy appointments and three of the four accepted. One was then referred on to her local CAMHS team (Child and Adolescent Mental Health Services) although failed to attend appointments. Psychological difficulties included one patient with flashbacks and nightmares relating to the FGM. Six children were extremely anxious about the consequences for their parents, and whether they might be removed from their families, even if this was not a real possibility. Parents of children who were not found to have FGM were very angry that they had been falsely accused and unnecessarily investigated. The response of anger and feelings of humiliation was worked through to some extent in the psychotherapeutic interview.

Circumstances varied for the 20 children where FGM was not found. In one, a midwife referred a 5-year-old girl despite her pregnant mother denying FGM had been performed on her daughter. In six cases, the referral was made following an anonymous referral to the police or during a family or work dispute. In two cases, the families came from non-practicing communities in Algeria and India.

\section{DISCUSSION}

Main findings

This is the first prospective study of children referred to clinical services with suspected or confirmed FGM living in a high income country. The only previous report in the literature is a retrospective study from the same authors (DH and SMC) describing 48 children seen over an 8-year period up to $2014 .^{5}$ Key clinical findings were similar in this study namely a young age at FGM, a large proportion of type 4 FGM and evidence of medicalisation. This reflects patterns reported in the 2013 UNICEF report of 29 countries in Africa and the Middle East. $^{9}$ Most referrals to the clinic were children of African origin but did include children from the Middle East and Asia reflecting the widespread nature of the practice. New findings included referrals following anonymous calls to police and referrals of children from non-practising backgrounds. A significant proportion of girls with type 4 FGM had minimal or no scarring and if paediatricians and gynaecologists do not have appropriate clinical expertise, then these cases will be missed.

\section{Strengths and limitations}

This data describe the characteristics of children referred to a clinical team with many years of experience in safeguarding children and in working with survivors of FGM and their families and provides clinical information about children living in the UK from FGM practising communities. The final criminal outcomes are unknown as legal proceedings are still on-going. More research on the psychological impact of referral to the clinic is awaited.
The number of referrals of children in this study with confirmed FGM is small in comparison with the numbers expected if all daughters of adult women living in the UK with FGM undergo FGM. It is unclear whether these small numbers are due to a trend to type 4 FGM where medical complications and physical signs are few, that children are being taken out of the UK for FGM or that FGM among children living in the UK is very uncommon.

\section{Interpretation}

Increased awareness of FGM particularly high-profile media campaigns ${ }^{10}{ }^{11}$ may have led to the increase in referrals since $2007 .{ }^{5}$ Other factors include new training for National Health Service (NHS) staff, ${ }^{12}$ updated professional guidance including the requirement to ask all pregnant women about FGM, ${ }^{13}{ }^{14}$ and focused advice about safeguarding children with FGM. ${ }^{13}$ Mandatory reporting of under 18s with FGM is now law ${ }^{2}$ and was introduced into practice on 31.10.15. Failure to report will carry sanctions including referral to regulatory bodies. All newly reported cases will need a clinical evaluation and it is unclear where and how these children and their families will be assessed. Children should be seen in an appropriate setting by professionals with the right clinical expertise. The effect of clinical assessment on children and their families is as yet unknown. In addition the impact of mandatory reporting on FGM practising communities was not evaluated prior to the introduction of the legislation. Concern has been expressed that it may deter families from seeking healthcare for their children.

Genital examination must be done with sensitivity by doctors with knowledge of normal and abnormal female genital anatomy. Guidelines suggest that the detection of FGM will be very obvious but this study highlights that this is not the case. Type 4 FGM may leave no visible trace or a small scar which must be distinguished from congenital variations and irregularities which are hard to detect even by experienced users of the colposcope. Obstetricians, gynaecologists and midwives managing adult FGM survivors may be asked to see children with suspected FGM. They must work jointly with safeguarding paediatricians familiar with genital examination in young children and with the use of the colposcope to magnify and photograph findings.

Safeguarding paediatricians must be aware of all types of FGM. Genital examination in children is most commonly done for suspected sexual abuse and focuses on the hymen and anus. Assessment for FGM must also demonstrate the clitoral and periclitoral area. Clinical findings must be documented and able to be presented in a court of law. Clinical experts in the management of adult FGM survivors who act outside their areas of expertise in this field do immeasurable harm to children by failing to detect FGM but also by erroneously diagnosing FGM when it has not occurred. ${ }^{15}$ The ideal setting for examination of these children will vary around the 
UK but should be within paediatric services. Only one child was referred to the clinic with FGM-related symptoms emphasising the fact that it is rarely the complications of FGM that lead to a referral and diagnosis.

The proportion of children in this study found to have type 4 FGM is a new and important finding. The number of children in this study is small but given that the majority of girls originated from Somalia where type 3 FGM is more common, these findings are unexpected. It is possible this demonstrates a move towards abandonment of the practice as the health risks of type 4 FGM are generally lower than the other types of FGM. Type 4 FGM is defined by the $\mathrm{WHO}$ as including pricking, piercing, incising, scraping and cauterisation (table 1). A 'ritual nick' has been controversially proposed in the past as an alternative ritual which causes less tissue damage and less long-term health consequences. ${ }^{16}$ Families must be made aware that even a small incision or prick is FGM and is not legal or acceptable. In addition health professionals must be able to recognise type 4 FGM and to advise families correctly as to the legal implications.

FGM is child abuse and there are established referral pathways where abuse is suspected. ${ }^{17}$ A referral is made to the Multi-Agency Safeguarding Hub (MASH) and an initial strategy meeting is convened so that social care and police can plan further investigations. The timing of the medical examination may not be set at this meeting but requested later. This study highlights the importance of establishing the facts around FGM and including examining girls at the earliest stage possible, taking into account the need for the criminal investigation. None of the children referred to this service needed urgent medical treatment for recent FGM but all needed confirmation-or refutation-of FGM. A mean time of 7 weeks before a referral was made to the FGM clinic is unacceptably long. This study demonstrated significant psychological stress for families during the early stages of the investigation particularly when they knew they were innocent of FGM. The long-term impact of referral on the family is unknown. Fear, shame, stigma and resentment are very powerful emotions which are not just personal but have strong components of cultural and even racial sensitivities. It is likely that immediate psychotherapeutic work can help to address these feelings and research is required into this. The importance of an experienced child psychotherapist or psychologist available to deal with these situations acutely cannot be underestimated.

In cases of suspected (but not confirmed) FGM, the clinical assessment should take place as soon as reasonably possible. This would allow a more efficient use of resources for social care, police and health. If the child has not had FGM but is still judged to be at risk, then a prevention pathway must be instigated to ensure FGM is not carried out in the index girl or the siblings.

In some cases, clinical referral could have been avoided entirely if police and social services were better informed about the practice of FGM. Despite training received by these professional groups, families from nonpracticing backgrounds were investigated. While the increasing reporting rates are welcomed, not all allegations arise out of genuine concern. Referrals were made after anonymous calls to the police from members of the public and in some cases were ill-informed. In the current climate of heightened concern about FGM, a single anonymous telephone call prompts a social care and police investigation of the family and is a powerful weapon to unleash in a family or work dispute. A prompt medical assessment to clarify whether or not FGM has been performed is particularly crucial in these situations.

\section{CONCLUSION}

\section{Practical recommendations}

Urgent attention should be given to the provision of multidisciplinary clinical services for children with confirmed or suspected FGM. These should be appropriately staffed by paediatricians and gynaecologists who have the necessary expertise. Children should be seen quickly so that when FGM is suspected there can be certainty as to whether or not it has been done. When confirmed, specific health interventions such as testing for BBV and deinfibulation maybe needed. Other children in the family may have had FGM or be at risk and it is essential to ensure parents are aware of the legal status and health implications of FGM. If a crime has been committed, the police will act accordingly and so accurate medical records and photo documentation are crucial.

\section{Research recommendations}

There is a lack of data on the risk for girls living within the diaspora communities. A forthcoming prospective study by the British Paediatric Surveillance Unit (BPSU) will identify the number of children identified by paediatricians and paediatric surgeons and will be combined with data collection from the Department of Health.

There is no research on the psychological impact of FGM on children and their families nor on the impact of the stigma for British girls whose mothers have had FGM. With increasing referral numbers, the effect on girls and their families of a referral for suspected FGM, regardless of whether or not FGM is confirmed, will be important to analyse.

Further research on FGM trends within FGM practising communities is essential. The unexpectedly high proportion of girls in this study with type 4 FGM may indicate families are changing practices and this needs further exploration.

Contributors SMC saw and examined all patients in clinic, advised on the study, reviewed the data and co-wrote the paper. JD collected data and wrote initial draft of the paper. CdC saw all patients in clinic and collected data. LW saw all patients in clinic and collected data. DH saw and examined all patients in clinic, advised on the study, reviewed the data and co-wrote the paper. 
Funding This research received no specific grant from any funding agency in the public, commercial or not-for-profit sectors.

Competing interests None declared.

Ethics approval The local Research Ethics Committee approved the study, providing all patient identifiable information was removed prior to analysis and publication.

Provenance and peer review Not commissioned; externally peer reviewed.

Data sharing statement No additional data are available.

Open Access This is an Open Access article distributed in accordance with the Creative Commons Attribution Non Commercial (CC BY-NC 4.0) license, which permits others to distribute, remix, adapt, build upon this work noncommercially, and license their derivative works on different terms, provided the original work is properly cited and the use is non-commercial. See: http:// creativecommons.org/licenses/by-nc/4.0/

\section{REFERENCES}

1. Female Genital Mutilation Risk and Safeguarding; Guidance for professionals, Department of Health Guidance, Published date: March 2015. https://www.gov.uk/government/uploads/system/ uploads/attachment_data/file/418564/2903800_DH_FGM_ Accessible_v0.1.pdf (accessed 18 Aug 2015).

2. Female Genital Mutilation. Government Legislation. Serious Crime Act. 2015 c.9 Part 5. http://www.legislation.gov.uk/ukpga/2015/9/part/ 5/crossheading/female-genital-mutilation/enacted (accessed 18 Aug 2015)

3. Hodes D, Creighton SM. Female Genital Mutilation: what every paediatrician should know. Arch Dis Child 2016;101:267-71.

4. Dawson A, Homer CS, Turkmani S, et al. A systematic review of doctors' experiences and needs to support the care of women with female genital mutilation. Int J Gynecol Obstet 2015;131:35-40.

5. Hodes D, Armitage A, Robinson K, et al. Female genital mutilation in children presenting to a London safeguarding clinic: a case series. Arch Dis Child 2016;101:212-16.
6. World Health Organization. Female genital mutilation: report of a WHO technical working group. Geneva: Division of Family Health, 17-19 July 1995. http://www.who.int/reproductivehealth/topics/fgm/ overview/en (accessed 19 Aug 2015).

7. Foundation for Women's Health Research and Development. http:// www.forwarduk.org

8. A Statement Opposing Female Genital Mutilation. November 2014 Home Office Guidance. https://www.gov.uk/government/publications/ statement-opposing-female-genital-mutilation (accessed 24 Aug 2015).

9. Female Genital Mutilation/Cutting: A Statistical Overview and Exploration of the Dynamics of Change. UNICEF Report 2013. http:// www.childinfo.org/files/FGCM_Lo_res.pdf (accessed 26 Aug 2015).

10. Female genital mutilation increase in England 'only tip of iceberg'. Tran M. The Guardian 30 April 2015. http://www.theguardian.com/ society/2015/apr/30/female-genital-mutilation-england-fgm-girls (accessed 19 Aug 2015)

11. Women with vagina piercings to be classed as suffering from FGM. Bentham M. The Evening Standard 17 March 2015. http://www. standard.co.uk/news/health/women-with-vagina-piercings-to-beclassed-as-suffering-from-fgm-10113202.html

12. Health Education England. E-learning to improve awareness and understanding of FGM. 2015. http://www.e-lfh.org.uk/programmes/ female-genital-mutilation (accessed 19 Aug 2015).

13. Female Genital Mutilation and its Management. Royal college of obstetricians and gynaecologists green top guidelines No 53. London: RCOG, 2015. https://www.rcog.org.uk/en/guidelinesresearch-services/guidelines/gtg53/

14. Female Genital Mutilation. Royal College of Nursing Guidance. 2015. http://www.rcn.org.uk/_data/assets/pdf_file/0010/608914/ RCNguidance FGM WEB2.pdf

15. Royal Courts of Justice. Case No: LJ13C00295. Sir James Munby 2015 https://www.judiciary.gov.uk/wp-content/uploads/2015/01/ BandG_2_.pdf

16. Ritual Genital Cutting of Female Minors. American Academy of Pediatrics Policy Statement Committee on Bioethics. Retirement of policy 126(1):177.

17. Working together to safeguard children-A guide to inter-agency working to safeguard and promote the welfare of children. DFE-00130-2015. 